Article

\title{
The Time-Series of Energy Mix and Transition: A Comparative Study of OECD Countries through the Fuzzy-Set Analysis
}

\author{
Taewook Huh ${ }^{1, *(\mathbb{D})}$, Yong-Chan Choi ${ }^{2}$ and Jiyoung Hailiey Kim ${ }^{3}$ \\ 1 Graduate School of Future Strategy, KAIST (Korea Advanced Institute of Science \& Technology), \\ Daejeon 34141, Korea \\ 2 Strategic Planning Center, KAIST (Korea Advanced Institute of Science \& Technology), Daejeon 34141, \\ Korea; ycchoi@kaist.ac.kr \\ 3 Graduate School of International Studies, Seoul National University, Seoul 08826, Korea; \\ koomikki@gmail.com \\ * Correspondence: twhuh@kaist.ac.kr
}

Received: 20 September 2018; Accepted: 30 October 2018; Published: 1 November 2018

check for updates

\begin{abstract}
This study aims to analyze the global trends of energy mix and energy transition from a chronological view (from Y1995 to Y2015) and identify the actual results based on the empirical findings. It sets up a measurement framework of energy mix (four energy sources: fossil fuel $(\mathrm{F})$, hydroelectric $(\mathrm{H})$, renewable $(\mathrm{R})$, and nuclear $(\mathrm{N})$ ), and compares thirty-four Organisation for Economic Cooperation and Development (OECD) countries' cases through the fuzzy-set ideal type analysis. In short, twelve ideal types of energy mix of the thirty-four OECD countries were derived in Y1995; eleven ideal types in Y2000, thirteen ideal types in Y2005, twelve ideal types in Y2010, and fifteen ideal types in Y2015, respectively. This study particularly reveals the gradual change of the features of energy transition, although an epoch-making trend of overall energy transition in OECD countries is not identified. For example, from1995 to 2010, in the case of Type 7 ( $\left.F^{*} h^{*} r^{*} N\right)$ with a characteristic of 'pan-conventional energy-centered mix' having two high features $(\mathrm{F}, \mathrm{N})$, and of Type $8\left(F^{*} h^{*}{ }^{*} n\right)$, characterized by 'fossil fuel-centered energy mix' with one high feature (F), seven to eight countries were steadily included, but in 2015 there was a significant decrease to four countries (solely Type 7). Throughout the five stages from 1995 to 2015, the type with the largest number of countries (20) was Type $10\left(f^{*} \mathrm{H}^{*} \mathrm{R}^{*} \mathrm{n}\right.$, 'pan-renewable energy-centered type') led by hydroelectric $(\mathrm{H})$ and renewable energy sources $(\mathrm{R})$, followed by the second most, Type $12,\left(\mathrm{f}^{*} \mathrm{H}^{*} \mathrm{r}^{*} \mathrm{~N}\right.$, 'hydro \& nuclear-centered type', characterized the high features of $\mathrm{H}$ and $\mathrm{N}$ ) with nineteen countries.
\end{abstract}

Keywords: Energy Mix; energy transition; OECD countries; Fuzzy-set Ideal Type Analysis

\section{Introduction}

Entering the 21st century, major changes in the energy environment have been taking place around the world [1,2]. Measures to reduce the use of fossil fuels due to greenhouse gas problems related to the global warming have been intensively discussed by developed countries in the Organisation for Economic Cooperation and Development (OECD), and extensive changes in energy technology and policy environment, in particular, are in progress [3]. Since the transition to the New Climate Regime after the Paris Agreement in December 2016, the energy sector is responsible for more than $2 / 3$ of greenhouse gas emission in the world, and has been drawing attention as a necessary sector to consider. In other words, an exhaustive reshuffling of existing fossil fuel-oriented energy policies is required. In this flow, 'Energy Mix' and 'Energy Transition' are emerging as global subjects [4-6]. 
'Energy Mix', a solution for more efficient energy use, refers to the diversification of an energy source [7]. It includes adequately counteracting skyrocketing energy demand through efficient utilization of 'existing energy' such as oil and coal, and fusion of 'new energy sources' such as Solar Photovoltaic [3,4]. Particularly, energy-importing countries are paying close attention to efficiently leading Energy Mix Policy as a solution to strengthen currently unstable energy security [6,7]. The global flow of the Energy Mix can be characterized by the decreasing coal power generation and increasing natural gas and renewable energy among OECD countries since the 2000s $[6,8,9]$. This seems to be complexly due to energy security, an economic factor, and an environmental factor, such as international issues related to climate change raise concern about the limits of available resources, such as coal depletion and a price drop of natural gas [10-12].

Meanwhile, Energy Transition is one of the major fields in system transformation policy, and it refers to a transition from a supply-oriented centralized energy system mainly dominated by fossil fuels and nuclear power energy to an energy system that focuses on demand management such as expansion of support for renewable energy, energy savings, improvement of efficiency, and a reduction in energy consumption $[13,14]$. With the principle for expansion of renewable energy for Energy Transition, various policy experiments are taking place and expanding around the world, which relate to the restructuring thermal power plants, accelerated integration into the expansion of renewable energy and existing energy system, the expansion of the power grid, energy efficiency enhancement through smart grid and storage devices, and expanding high energy-efficient buildings [2,3].

However, on the other hand, criticism that the Energy Transition has not really occurred and that changes in the economic and social system to achieve Energy Transition are still far-off remains [9]. According to the international comparative analysis of LCOE (Levelized Cost of Electricity) by the International Energy Agency (IEA), countries such as Korea and Japan, where the use of renewable energy is not accompanied by economies of scale due to geographical limitations, are forecasting that the economics of renewable energy is low, unlike the LCOE forecasts of major energy economies in the US and Europe $[9,15,16]$. In the end, even in the advanced countries of OECD, it is emphasized that regardless of considering the social and environmental costs, if there is no remarkable advancement in green technology, it will be difficult for renewable energy to reverse the economic feasibility of nuclear power generation in the medium and long term $[3,17]$.

Considering these arguments (both pros and cons), this paper aims to analyze the global trends of energy mix and energy transition in chronological order (from Y1995 to Y2015) and identify the actual results based on the empirical findings. Focusing on the worldwide trend of energy mix and energy transition, this study attempts to set out four variables: fossil fuel, hydroelectric, renewable, and nuclear energy sources through the fuzzy-set analysis, a comparative research methodology. Then it draws on the findings of the ideal types of energy mix through the fuzzy-set ideal type analysis (STATA 12.0 used). In short, this paper explores the following research question. How do the ideal types of the energy mix in the OECD countries form and what implications do they have in the context of energy transition? In this study, thirty-four OECD countries (valid data from all thirty-five OECD member countries) were selected as the cases by extracting related data (variables) on the four variables of energy mix.

This paper is structured as follows, in Section 2; we discuss the theoretical background and issues of energy mix and energy transition. In Section 3, we explain the rationale of the fuzzy-set analysis methodology and set up the measurement frameworks including the variable composition of the ideal type analysis. In Section 4, we present the findings of the fuzzy-set ideal type analysis, and the implications for the case countries.

\section{Theoretical Background of Energy Mix and Energy Transition}

Energy Mix plans for each of the OECD countries contain various global and national environmental changes. Especially, the environmental changes which have already been advancing or which will be realized in the near future are subjects [3]. As factors most strongly affect the global 
environmental changes in the energy sector emerging since the 21st century, first, the reduction in fossil fuel usage can be considered to decrease greenhouse gas as use of the fossil fuels cause global warming. Second, the stressing of new and renewable energy: Renewable energy, in particular, has been pronounced as being at the center of the recent Energy Mix agendas, as it was pointed out to be the capable of achieving a reduction in greenhouse gas and energy security against high oil prices, and green growth through the export of technologies altogether [5,17]. Although there is no internationally fixed definition and scope for renewable energy, in general, it can be defined as energy used by transforming the existing fossil fuels or the renewable energy that include sunlight, water, geothermal heat, rainfall precipitation, and biological organisms [6]. There are nine types of main renewable energy source: Solar Photovoltaic, solar heat, wind power, hydropower, ocean, geothermal heat, and bio- and hydrothermal energy. New energy types include fuel cell, hydrogen energy, and coal gasification [17].

Also, the energy that received the spotlight from the 21st century due to the aftermath of the greenhouse gas reduction and high oil prices is nuclear power. Although nuclear power has advantages to have nearly no emission of greenhouse gas and the lowest generating cost, due to the risks of nuclear power accident, exhaustiveness of the ingredient Uranium, and problems with management costs in the future, arguments against the use of nuclear power have been articulated [3,9]. In the perspective of setting an Energy Mix, since nuclear power plants are facilities that cause large capital investment and it is most cost-effective to maximize use once they are built, it is important to discuss nuclear plants by distinguishing ones for which investment decisions have already been made and the others that are yet in planning.

Meanwhile, in cases of some OECD countries (Korea, Japan, etc.), promoting export-industrialization policy for the energy industry and its application to the Energy Mix an important issue [3,17]. As firms in relevant countries are pursuing exports through oil product exports, nuclear power plant construction orders, and package-deals for overseas resource development, a correlation between Energy Mix and international competitiveness enhancement and maintenance policies has become more significant. In other words, the subject of discussion has been whether to adjust domestic Energy Mix according to the ripple effects of fostering and exporting of domestic industries.

In terms of global power production structure by generation sources, coal generation has been significantly decreasing in OECD countries which was replaced by natural gas generation, and noticeably, there is a rapid increase in renewable energy generation after the 2000s $[9,10]$. The weight of each generation source of OECD countries has different characteristics depending on their national conditions, and along with the flow of the era, it can reflect advents of new generation source and changes in the weight.

Coal generation, in particular, has been most widely used as one of the oldest base-load generation sources, however, as new power generation fuels such as nuclear power and natural gas appeared, countries are experiencing major changes in their composition of power generation sources. Nuclear power generation appeared during the 1970s and 1980s while natural gas appeared after the 1980s and proliferated thereafter, and as concerns about environmental pollution caused by greenhouse gas omission raised in international conventions appeared, from the 2000s onwards interests in renewable energy generation and technological innovation have been continuing [6,9].

Power mix and capacity factors show large disparities by country because they are determined by power consumption patterns of each country, generation cost, national policy, and energy plans, efficiency level of generation technologies, and availability of generation source [11]. Power is a country's key industry; but because power generated cannot be readily stored, it can be influenced absolutely by distribution prediction and amount of consumption according to a government's power plans.

Meanwhile, major countries in OECD are promoting policies that focus on reducing the use of fossil fuels (carbon reduction) and expanding renewable energy use, while they are also increasingly trying to reduce the use of nuclear energy due to numerous nuclear power accidents that have 
happened almost once in every 10 years [3,12]. In fact, these efforts for 'energy transition' pursue the 'soft energy path' [3,18], which was suggested almost 40 years ago. The ideas of 'energy transition' emphasizes on transition of 'sociotechnical system' in which political, economic, and social elements also change and become restructured, along with transition of the 'energy source' from fossil fuel and nuclear power generation, the hard energy path, into renewable energy, the soft energy path [19-21].

The transition that sociotechnical system theory focuses on refers to a gradual and continuous structural transition process which takes place in a given social system for more than one generation (30 years); this transition is fundamentally based on a multi-level perspective and transdisciplinary approach; the basic transition process is to have a system transformation happen by producing interactions between scientific technology and society and, through this, bring positive policy changes [22,23]. Lately, in terms of scrutinizing and theorizing this systemic property of energy transition, a theoretical approach called 'transition studies' has been drawing attention which analyzes and studies changes and relevant policies of a sociotechnical system [24-26].

As one of the major examples of energy transition, the German Government announced 'Energy Transition (Energiewende)' for a total energy system transition in 2009 and has been searching for changes in energy policy and regulation method [21]. Especially, it announced the 'Energy Concept $2010^{\prime}$, which addresses plans to decrease dependency on fossil fuel energy and to expand new and renewable energy sources and, ultimately, to shut down all their nuclear power plants. In specifics, alerted by the Fukushima Daiichi nuclear disaster, the German Government decided to shut down all of its nuclear power plants by 2022 and drew worldwide attention by announcing an 'Energy Package' amended from the previous Energy Concept [5,21]. In addition, since the Fukushima Daiichi nuclear disaster in 2001, France mapped out 'Energy Transition' in order to deal with concerns of nuclear power safety from media and to secure diversity of energy source, and legislated <Energy Transition Law > in 2015; the Energy Transition Law contains, as major policy goals, combating climate change through greenhouse gas reduction, new and renewable energy expansion, reduction of dependence on nuclear power development, and energy source diversification $[17,27,28]$.

\section{Fuzzy-Set Methodology and Measurement Framework}

\subsection{The Rationale of Fuzzy-Set and Ideal Type Analysis}

The Fuzzy-set Analysis (methodology) is a special form of case study method as Qualitative Comparative Analysis (QCA) suggested by Zadeh from the University of Berkeley in 1965, and it has been used in diverse ways by scholars such as Ragin and Kvist in application to Social Sciences [29,30]. The Fuzzy-set analysis is an improved version of the method from Qualitative Comparative Analysis [31,32] that was previously used in the Social Sciences. In particular, Fuzzy-set analysis has a set of major advantages. First, through exercising Fuzzy-set methodology, disadvantages of case-oriented study and variable-oriented study can be overcome. It can be said that case-oriented analysis deals with a particular phenomenon in depth, whilst quantity-oriented analysis puts its emphasis on generalities of various cases by using variables [31]. Second, due to this property, Fuzzy-set analysis enables dealing of the middle-case studies (15-25 cases), which comparative case analysis and regression analysis could not address despite being substantial subjects for analysis, and makes middle-class comparative analysis possible [29,31]. Moreover, it is also used in analyzing joint causal relations by paying due consideration to interactive effects between each quality in a given case $[29,30]$. Third, it can explain diverse social phenomena. Although a great number of social scientists confront situations of analyzing complicated social phenomena, in practical analysis there have been many cases where they simply categorize the social phenomenon in a dichotomy of 0 and 1 , which minimizes the loss of information in the analysis [31,33]. Fourth, it enables a more theoretical approach to categorization of the types $[34,35]$. The Fuzzy-set analysis determines the number of memberships by categorization standards that consist of the ideal type extracted under theoretical 
background $[29,36]$. Accordingly, many recent studies are applying Fuzzy-set analysis to categorizing types $[37,38]$.

This research categorizes thirty-four OECD countries through comparative analysis by utilizing Fuzzy-set Ideal Type Analysis. Fuzzy-set Ideal Type Analysis represented by fuzzy membership scores demonstrates, by applying Fuzzy-set Theory, how close the subject of analysis is to that converted into fuzzy sets $[39,40]$. Through this process it analyzes the degree of memberships of each category, translating the existing original data results into fuzzy-set membership scores. As the number of the sets is decided by the ideal type, unlike the existing cluster analysis through Fuzzy-set Ideal Type Analysis which this research conveys, more systematic categorization and interpretation become available [37,38].

The criteria for interpretation of membership scores of Fuzzy-set Ideal Type Analysis drawn from this research is based on the one suggested by Ragin [32]. In particular, after we converted the scores into the Fuzzy-set score system through the calibrate function of STATA 12.0, we have measured them according to three qualitative anchors: 'fully in', 'fully out', and 'crossover point' as in the degree of the two. In other words, any score that is higher than the crossover point (0.5) is given strong membership (in the case the degree of full membership the given value possesses (FI: fully in or full membership) is higher than $95 \%$ (0.95)). In addition, any score below is given a low membership score (in the case the degree of full membership is not present (FO: fully out or full non-membership) is lower than $5 \%(0.05)$ ). The formula for the Degree of Membership Score in the Fuzzy-set Idea Type Analysis is as follows

- Degree of Membership $=\exp (\log$ odds $) /(1+\exp (\log$ odds $)$.

\subsection{Measurement Frameworks}

In order to conduct the Fuzzy-set ideal type analysis, this study first sets up the four type variables (fossil fuel energy sources, hydroelectric sources, renewable sources, and nuclear sources). Second, it converted (calibrated) the four type variables into fuzzy scores by utilizing the three anchors (minimum, median (p50), and maximum), respectively, in order to identify the types of energy mix in thirty-four OECD countries from Y1995 to Y2015.

The degree of membership in this research is calculated and interpreted by the 'principle of negation', the 'minimum principle', and the 'maximum principle'. This research sets the four category variables 'fossil fuel sources'(F), 'hydroelectric sources' (H), 'Renewable sources' (R), 'Nuclear sources' $(\mathrm{N})$, as shown in Table 1. In this case, the principle of negation enables setting up negative categories of ' $f$ ', ' $h$ ', ' $r$ ', and ' $n$ ' through '1-Fuzzy-set membership score of the applicable category'. Accordingly, the ideal type is determined by applying the number of cases that each category variable can take, and this research postulates sixteen ideal type sets (high or low) based on the four category variables (see Table 2).

In addition, these sixteen ideal type sets are yielded and interpreted by the 'Minimum Principle' and the 'Maximum Principle' $[38,46]$. The 'Minimum Principle' states that it is the minimum value among the fuzzy-set scores drawn from the principle of the sixteen types of ideal type categorization that will be the Fuzzy-set membership score of the respective categories; in other words, among the fuzzy scores of the four variables $(\mathrm{F}, \mathrm{H}, \mathrm{R}, \mathrm{N})$ that consist of the corresponding category sets, the minimum value will be selected. For example, if the fuzzy score of $F$ in Category ${ }^{\prime} \mathrm{F}^{*} \mathrm{H}^{*} \mathrm{R}^{*} \mathrm{~N}$ ' appears to be the minimum value, the fuzzy-set membership score of Category ' ${ }^{*} \mathrm{H}^{*} \mathrm{R}^{*} \mathrm{~N}^{\prime}$ will be denoted as the fuzzy score of ' $F$ ' itself. Moreover, the 'Maximum Principle' postulates that while the fuzzy-set membership score of twenty-four OECD countries can conclusively be presented by sixteen types of categories, one with the maximum value of the membership score will be the category for the corresponding area. 
Table 1. The Variable Framework of the ideal type analysis.

\begin{tabular}{|c|c|c|c|c|}
\hline Type & Variables & Type & Variables & References \\
\hline $\mathbf{F}$ & $\begin{array}{c}\text { fossil fuel sources } \\
\text { (including coal, oil, natural } \\
\text { gas, \% of total) }\end{array}$ & $\mathbf{R}$ & $\begin{array}{c}\text { renewable sources } \\
\text { (excluding hydroelectric, } \\
\% \text { of total) }\end{array}$ & \multirow{2}{*}{$\begin{array}{c}\text { WB World } \\
\text { Development Indicators } \\
(1995 \text { [41], } 2000 \text { [42], 2005 } \\
{[43], 2010 \text { [44], 2015 [45]) }}\end{array}$} \\
\hline $\mathbf{H}$ & $\begin{array}{c}\text { hydroelectric sources } \\
\text { (\% of total) }\end{array}$ & $\mathbf{N}$ & $\begin{array}{l}\text { nuclear sources } \\
\text { (\% of total) }\end{array}$ & \\
\hline
\end{tabular}

Table 2. The Sixteen Ideal Type Sets.

\begin{tabular}{|c|c|}
\hline Ideal Type & Features of Types \\
\hline 1: $\mathbf{F}^{*} \mathbf{H}^{*} \mathbf{R}^{*} \mathbf{N}$ & High Fossil Fuel, Hydroelectric, Renewal, Nuclear Energy Sources \\
\hline 2: $\mathrm{F}^{*} \mathrm{H}^{*} \mathrm{R}^{*} \mathrm{n}$ & High Fossil Fuel, Hydroelectric, Renewal, \& low nuclear energy sources \\
\hline 3: $\mathrm{F}^{*} \mathrm{H}^{*} \mathrm{r}^{*} \mathrm{~N}$ & High Fossil Fuel, Hydroelectric, Nuclear \& low renewal energy sources \\
\hline 4: $\mathrm{F}^{*} \mathrm{H}^{*} \mathrm{r}^{*} \mathrm{n}$ & High Fossil Fuel, Hydroelectric, \& low renewal, nuclear energy sources \\
\hline 5: $\mathrm{F}^{*} \mathrm{~h}^{*} \mathrm{R} * \mathrm{~N}$ & High Fossil Fuel, Renewal, Nuclear \& low hydroelectric energy sources \\
\hline 6: $F^{*} h^{*} R^{*} n$ & High Fossil Fuel, Renewal, \& low hydroelectric, nuclear energy sources \\
\hline 7: $\mathrm{F}^{*} \mathrm{~h}^{*} \mathrm{r}^{*} \mathrm{~N}$ & High Fossil Fuel, Nuclear \& low hydroelectric, renewal energy sources \\
\hline 8: $\mathrm{F}^{*} \mathrm{~h}^{*} \mathrm{r}^{*} \mathrm{n}$ & High Fossil Fuel \& low hydroelectric, renewal, nuclear energy sources \\
\hline 9: $\mathrm{f}^{*} \mathrm{H}^{*} \mathrm{R}^{*} \mathrm{~N}$ & Low fossil fuel \& High Hydroelectric, Renewal, Nuclear Energy Sources \\
\hline 10: $f^{*} H^{*} R^{*} n$ & Low fossil fuel, nuclear \& High Hydroelectric, Renewal Energy Sources \\
\hline 11: $f^{*} h^{*} R^{*} N$ & Low fossil fuel, hydroelectric \& High Renewal, Nuclear Energy Sources \\
\hline 12: $\mathrm{f}^{*} \mathrm{H}^{*} \mathrm{r}^{*} \mathrm{~N}$ & Low fossil fuel, renewal \& High Hydroelectric, Nuclear Energy Sources \\
\hline 13: $\mathrm{f}^{*} \mathrm{H}^{*} \mathrm{r}^{*} \mathrm{n}$ & Low fossil fuel, renewal \& High Hydroelectric Energy Sources \\
\hline 14: $f^{*} h^{*} R^{*} n$ & Low fossil fuel, hydroelectric, nuclear \& High Renewal Energy Sources \\
\hline 15: $f^{*} h^{*} r^{*} \mathrm{~N}$ & Low fossil fuel, hydroelectric, renewal \& High Nuclear Energy Sources \\
\hline 16: $f^{*} h^{*} r^{*} n$ & Low fossil fuel, hydroelectric, renewal, nuclear energy sources \\
\hline
\end{tabular}

\section{Findings: Changes and Continuity of Energy Mix and Transition}

As explained in Table 3 below, the changes in the energy mix of the 34 OECD countries by year are shown in the descriptive statistics. The energy source with the most rapid change was renewable energy sources, which was only $1.9 \%$ (of total energy generation) in 1995, but it increased to $15.1 \%$ in 2015, showing an increase of approximately 8 times. Among the 34 OECD countries in 1995, the maximum (Finland case) of the rate of generation of renewable energy sources was $10.3 \%$, but in 2015 the maximum (Denmark case) reached $60.7 \%$. On the other hand, fossil fuel sources accounted for the highest percentage of 55.8\% in 1995 and 48.3\% in 2015, but the share of fossil fuel sources decreased by $15 \%$ compared to 1995 . In addition, hydroelectric and nuclear sources have been found to have declined by about $21 \%$ and $4 \%$, respectively, over a period of 20 years. This study notes that the characteristics of gradual energy transition from the fossil fuel sources to the renewable energy sources have been achieved for 20 years since 1995.

Table 3. Descriptive Statistics of the 34 Organization for Economic Cooperation and Development (OECD) Countries' Energy Mix.

\begin{tabular}{|c|c|c|c|c|c|c|c|c|c|c|c|c|c|c|c|c|}
\hline \multirow[b]{2}{*}{ Year } & \multicolumn{4}{|c|}{ Fossil Fuel } & \multicolumn{4}{|c|}{ Hydro } & \multicolumn{4}{|c|}{ Renewable } & \multicolumn{4}{|c|}{ Nuclear } \\
\hline & mea & $\min$ & p50 & $\max$ & mear & $\min$ & p50 & $\max$ & mea & $\min$ & p50 & $\max$ & mea & $\min$ & p50 & $\max$ \\
\hline '95 & 55.8 & 0.2 & 61.4 & 99.9 & 24.4 & 0.0 & 14.4 & 99.4 & 1.9 & 0.0 & 0.8 & 10.3 & 16.3 & 0.0 & 2.5 & 76.8 \\
\hline${ }^{\prime} 00$ & 56.4 & 0.1 & 61.1 & 99.9 & 22.8 & 0.1 & 12.6 & 99.5 & 3.1 & 0.0 & 1.4 & 17.2 & 17.1 & 0.0 & 4.2 & 77.6 \\
\hline${ }^{\circ} 05$ & 57.6 & 0.1 & 64.1 & 100 & 19.6 & 0.1 & 7.6 & 98.9 & 4.6 & 0.0 & 2.7 & 27 & 17.4 & 0.0 & 4.2 & 79 \\
\hline${ }^{\prime} 10$ & 54.7 & 0.0 & 59.9 & 99.7 & 20.5 & 0.1 & 12.1 & 94.7 & 8.1 & 0.2 & 5.2 & 31.9 & 16.2 & 0.0 & 2.7 & 75.9 \\
\hline${ }^{15}$ & 48.3 & 0.0 & 53.6 & 97.8 & 20.1 & 0.0 & 9.9 & 95.8 & 15.1 & 1.0 & 12.5 & 60.7 & 15.6 & 0.0 & 2.2 & 77.7 \\
\hline
\end{tabular}

Through the Fuzzy-set ideal type analysis, twelve ideal types of the energy mix of thirty-four OECD countries were derived in Y1995, eleven ideal types in Y2000, thirteen ideal types in Y2005, 
twelve ideal types in Y2010, and fifteen ideal types in Y2015, respectively. The findings of the Fuzzy-set ideal type analysis on the energy mix for each of the thirty-four OECD countries are quite different for each year (see Tables 4 and 5 below). Luxembourg (Fuzzy-set membership score, 0.533) and Mexico (0.530) were included in Type $1\left(\mathrm{~F}^{*} \mathrm{H}^{*} \mathrm{R}^{*} \mathrm{~N}\right)$ in 1995, which has all four high features of energy sources (Fossil Fuel, Hydroelectric, Renewable, and Nuclear), and Mexico (0.502) was included again in 2005. However, Hungary (fuzzy-set membership score, 0.543) and Korea (0.501) in 1995 and Austria (0.759) in 2015 were included in Type $16\left(f^{*} h^{*} r^{*} n\right)$ with the four low features (fossil fuel, hydroelectric, renewable, and nuclear). Type $1\left(\mathrm{~F}^{*} \mathrm{H}^{*} \mathrm{R}^{*} \mathrm{~N}\right)$ can be regarded as a 'strong-balanced energy-mix' in which all four energy sources are well balanced at a high level, while Type $16\left(f^{*} h^{*} r^{*} n\right)$ seems to have a characteristic of 'weak-balanced energy-mix', structured in a balanced manner at a low level.

In particular, the changes and continuity results of the ideal types of the energy mix for each country are shown in Table 6 below. For 20 years from 1995 to 2015, twenty-four out of thirty-four countries showed a change in their ideal types more than once; ten countries from 1995 to 2000 , ten countries from 2000 to 2005, ten countries from 2005 to 2010, and eleven countries from 2010 to 2015. In particular, there are six countries (FRA, GER, HUN, LUX, NED, and ESP) with three or more changes of the energy mix ideal types, and six countries (CHI, GRC, JPA, KOR, MEX and UK) with two changes of the ideal types (all grey columns in Table 6 below). 
Table 4. Results of Fuzzy-set ideal type analysis by OECD countries (Y1995).

\begin{tabular}{|c|c|c|c|c|c|c|c|c|c|c|c|c|c|}
\hline Type & 1 & 2 & 5 & 6 & 7 & 8 & 9 & 10 & 12 & 13 & 15 & 16 & $T_{1}$ \\
\hline Country & $\mathbf{F}^{*} \mathbf{H}^{*} \mathbf{R}^{*} \mathbf{N}$ & $\mathbf{F}^{*} \mathbf{H}^{*} \mathbf{R}^{*} \mathbf{n}$ & $\mathbf{F}^{*} \mathbf{h}^{*} \mathbf{R}^{*} \mathbf{N}$ & $F^{*} h^{*} R^{*} n$ & $F^{*} h^{*} r^{*} N$ & $F^{*} h^{*} r^{*} n$ & $\mathbf{f}^{*} \mathbf{H}^{*} \mathbf{R}^{*} \mathbf{N}$ & $\mathbf{f}^{*} \mathbf{H}^{*} \mathbf{R}^{*} \mathbf{n}$ & $\mathbf{f}^{*} \mathrm{H}^{*} \mathbf{r}^{*} \mathbf{N}$ & $\mathbf{f}^{*} \mathbf{H}^{*} \mathbf{r}^{*} \mathbf{n}$ & $f^{*} h^{*} r^{*} N$ & $\mathbf{f}^{*} \mathbf{h}^{*} \mathbf{r}^{*} \mathbf{n}$ & Ideal Iype \\
\hline LUX & 0.533 & 0.199 & 0.467 & 0.199 & 0.273 & 0.199 & 0.321 & 0.199 & 0.273 & 0.199 & 0.273 & 0.199 & \multirow{2}{*}{ 1: $\mathbf{F}^{*} \mathbf{H}^{*} \mathbf{R}^{*} \mathbf{N}$} \\
\hline MEX & 0.530 & 0.470 & 0.467 & 0.467 & 0.180 & 0.180 & 0.325 & 0.325 & 0.180 & 0.180 & 0.180 & 0.180 & \\
\hline PRT & 0.047 & 0.594 & 0.047 & 0.406 & 0.047 & 0.319 & 0.047 & 0.309 & 0.047 & 0.309 & 0.047 & 0.309 & \multirow[b]{2}{*}{ 2: $\mathbf{F}^{*} \mathbf{H}^{*} \mathbf{R}^{*} \mathbf{n}$} \\
\hline ITA & 0.047 & 0.513 & 0.047 & 0.487 & 0.047 & 0.445 & 0.047 & 0.164 & 0.047 & 0.164 & 0.047 & 0.164 & \\
\hline USA & 0.237 & 0.237 & 0.594 & 0.329 & 0.406 & 0.329 & 0.237 & 0.237 & 0.237 & 0.237 & 0.358 & 0.329 & \multirow{3}{*}{ 5: $\mathbf{F}^{*} \mathbf{h}^{*} \mathbf{R}^{*} \mathbf{N}$} \\
\hline NED & 0.048 & 0.048 & 0.525 & 0.475 & 0.437 & 0.437 & 0.048 & 0.048 & 0.048 & 0.048 & 0.083 & 0.083 & \\
\hline JPN & 0.209 & 0.209 & 0.502 & 0.255 & 0.453 & 0.255 & 0.209 & 0.209 & 0.209 & 0.209 & 0.453 & 0.255 & \\
\hline DEN & 0.047 & 0.048 & 0.047 & 0.790 & 0.047 & 0.210 & 0.047 & 0.048 & 0.047 & 0.048 & 0.047 & 0.072 & 6: $\mathrm{F}^{*} \mathrm{~h}^{*} \mathrm{R}^{*} \mathrm{n}$ \\
\hline UK & 0.064 & 0.064 & 0.321 & 0.273 & 0.679 & 0.273 & 0.064 & 0.064 & 0.064 & 0.064 & 0.320 & 0.273 & \multirow{3}{*}{ 7: $\mathrm{F}^{*} \mathbf{h}^{*} \mathbf{r}^{*} \mathbf{N}$} \\
\hline CZE & 0.090 & 0.090 & 0.407 & 0.329 & 0.593 & 0.329 & 0.090 & 0.090 & 0.090 & 0.090 & 0.244 & 0.244 & \\
\hline GER & 0.105 & 0.105 & 0.499 & 0.258 & 0.501 & 0.258 & 0.105 & 0.105 & 0.105 & 0.105 & 0.423 & 0.258 & \\
\hline ISR & 0.047 & 0.047 & 0.047 & 0.047 & 0.047 & 0.952 & 0.047 & 0.047 & 0.047 & 0.048 & 0.047 & 0.048 & \multirow{6}{*}{ 8: $F^{*} h^{*} r^{*} n$} \\
\hline POL & 0.047 & 0.047 & 0.047 & 0.047 & 0.047 & 0.938 & 0.047 & 0.047 & 0.047 & 0.053 & 0.047 & 0.053 & \\
\hline EST & 0.047 & 0.047 & 0.047 & 0.068 & 0.047 & 0.932 & 0.047 & 0.047 & 0.047 & 0.047 & 0.047 & 0.047 & \\
\hline IRL & 0.047 & 0.068 & 0.047 & 0.068 & 0.047 & 0.895 & 0.047 & 0.064 & 0.047 & 0.064 & 0.047 & 0.064 & \\
\hline GRC & 0.047 & 0.068 & 0.047 & 0.068 & 0.047 & 0.774 & 0.047 & 0.068 & 0.047 & 0.089 & 0.047 & 0.089 & \\
\hline AUS & 0.047 & 0.182 & 0.047 & 0.182 & 0.047 & 0.747 & 0.047 & 0.095 & 0.047 & 0.095 & 0.047 & 0.095 & \\
\hline SWE & 0.060 & 0.060 & 0.060 & 0.060 & 0.060 & 0.060 & 0.571 & 0.141 & 0.429 & 0.141 & 0.248 & 0.141 & \multirow{4}{*}{ 9: $f^{*} H^{*} R^{*} N$} \\
\hline FIN & 0.255 & 0.248 & 0.255 & 0.248 & 0.047 & 0.047 & 0.551 & 0.248 & 0.047 & 0.047 & 0.047 & 0.047 & \\
\hline CAN & 0.124 & 0.124 & 0.124 & 0.124 & 0.124 & 0.124 & 0.516 & 0.353 & 0.484 & 0.353 & 0.167 & 0.167 & \\
\hline SUI & 0.051 & 0.051 & 0.051 & 0.051 & 0.051 & 0.051 & 0.508 & 0.180 & 0.492 & 0.180 & 0.185 & 0.180 & \\
\hline NZL & 0.047 & 0.097 & 0.047 & 0.097 & 0.047 & 0.097 & 0.047 & 0.892 & 0.047 & 0.108 & $\begin{array}{l}0.047 \\
\end{array}$ & 0.101 & \multirow{4}{*}{ 10: $f^{*} H^{*} R^{*} n$} \\
\hline CHI & 0.047 & 0.160 & 0.047 & 0.141 & 0.047 & 0.134 & 0.047 & 0.840 & 0.047 & 0.134 & 0.047 & 0.134 & \\
\hline ISL & 0.047 & 0.047 & 0.047 & 0.047 & 0.047 & 0.047 & 0.047 & 0.829 & 0.047 & 0.171 & 0.047 & 0.057 & \\
\hline AUT & 0.047 & 0.172 & 0.047 & 0.134 & 0.047 & 0.134 & 0.047 & 0.688 & 0.047 & 0.312 & 0.047 & 0.134 & \\
\hline SLO & 0.047 & 0.047 & 0.047 & 0.047 & 0.239 & 0.199 & 0.047 & 0.047 & 0.594 & 0.199 & 0.406 & 0.199 & \multirow{3}{*}{ 12: $f^{*} H^{*} r^{*} N$} \\
\hline SVK & 0.047 & 0.047 & 0.047 & 0.047 & 0.243 & 0.161 & 0.047 & 0.047 & 0.536 & 0.161 & 0.464 & 0.161 & \\
\hline FRA & 0.067 & 0.047 & 0.067 & 0.047 & 0.067 & 0.047 & 0.245 & 0.047 & 0.504 & 0.047 & 0.496 & 0.047 & \\
\hline NOR & 0.047 & 0.048 & 0.047 & 0.047 & 0.047 & 0.047 & 0.047 & 0.095 & 0.047 & 0.905 & 0.047 & 0.047 & \multirow{2}{*}{ 13: $\mathbf{f}^{*} \mathbf{H}^{*} \mathbf{r}^{*} \mathbf{n}$} \\
\hline TUR & 0.047 & 0.182 & 0.047 & 0.182 & 0.047 & 0.280 & 0.047 & 0.182 & 0.047 & 0.537 & 0.047 & 0.280 & \\
\hline BEL & 0.052 & 0.052 & 0.182 & 0.102 & 0.277 & 0.102 & 0.052 & 0.052 & 0.052 & 0.052 & 0.723 & 0.102 & \multirow[b]{2}{*}{ 15: $f^{*} h^{*} r^{*} N$} \\
\hline ESP & 0.382 & 0.222 & 0.382 & 0.222 & 0.382 & 0.222 & 0.474 & 0.222 & 0.474 & 0.222 & 0.500 & 0.222 & \\
\hline HUN & 0.047 & 0.052 & 0.047 & 0.095 & 0.047 & 0.457 & 0.047 & 0.052 & 0.047 & 0.052 & 0.047 & 0.543 & \multirow{2}{*}{$\underline{16: f^{*} h^{*} r^{*} n}$} \\
\hline KOR & 0.047 & 0.064 & 0.047 & 0.068 & 0.047 & 0.499 & 0.047 & 0.064 & 0.047 & 0.064 & 0.047 & 0.501 & \\
\hline
\end{tabular}


Table 5. Results of Fuzzy-set ideal type analysis by OECD countries (Y2015).

\begin{tabular}{|c|c|c|c|c|c|c|c|c|c|c|c|c|c|c|c|c|}
\hline Type & 2 & 3 & 4 & 5 & 6 & 7 & 8 & 9 & 10 & 11 & 12 & 13 & 14 & 15 & 16 & \multirow{2}{*}{ Ideal Type } \\
\hline Country & $\mathrm{F}^{*} \mathbf{H}^{*} \mathbf{R}^{*} \mathbf{n}$ & $\mathbf{F}^{*} \mathbf{H}^{*} \mathbf{r}^{*} \mathbf{N}$ & $F^{*} H^{*} r^{*} n$ & $\mathbf{F}^{*} \mathbf{h}^{*} \mathbf{R}^{*} \mathbf{N}$ & $F^{*} h^{*} R^{*} n$ & $F^{*} h^{*} r^{*} N$ & $F^{*} h^{*} r^{*} n$ & $\mathbf{f}^{*} \mathbf{H}^{*} \mathbf{R}^{*} \mathbf{N}$ & $\mathbf{f}^{*} \mathbf{H}^{*} \mathbf{R}^{*} \mathbf{n}$ & $f^{*} \mathbf{h}^{*} \mathbf{R}^{*} \mathbf{N}$ & $\mathbf{f}^{*} \mathbf{H}^{*} \mathbf{r}^{*} \mathbf{N}$ & $\mathbf{f}^{*} \mathbf{H}^{*} \mathbf{r}^{*} \mathbf{n}$ & $f^{*} h^{*} R^{*} n$ & $f^{*} h^{*} r^{*} N$ & $f^{*} h^{*} r^{*} n$ & \\
\hline AUS & 0.562 & 0.047 & 0.438 & 0.047 & 0.148 & 0.047 & 0.148 & 0.047 & 0.098 & 0.047 & 0.047 & 0.098 & 0.098 & 0.047 & 0.098 & \multirow{3}{*}{ 2: $F^{*} H^{*} R^{*} n$} \\
\hline ITA & 0.550 & 0.047 & 0.337 & 0.047 & 0.450 & 0.047 & 0.337 & 0.047 & 0.398 & 0.047 & 0.047 & 0.337 & 0.398 & 0.047 & 0.337 & \\
\hline GRC & 0.515 & 0.047 & 0.421 & 0.047 & 0.485 & 0.047 & 0.421 & 0.047 & 0.240 & 0.047 & 0.047 & 0.240 & 0.240 & 0.047 & 0.240 & \\
\hline MEX & 0.127 & 0.501 & 0.484 & 0.127 & 0.127 & 0.499 & 0.484 & 0.127 & 0.127 & 0.127 & 0.135 & 0.135 & 0.127 & 0.135 & 0.135 & 3: $\mathbf{F}^{*} \mathbf{H}^{*} \mathbf{r}^{*} \mathbf{N}$ \\
\hline TUR & 0.166 & 0.047 & 0.636 & 0.047 & 0.166 & 0.047 & 0.364 & 0.047 & 0.166 & 0.047 & 0.047 & 0.277 & 0.166 & 0.047 & 0.277 & \multirow{2}{*}{ 4: $F^{*} H^{*} r^{*} n$} \\
\hline CHI & 0.360 & 0.047 & 0.576 & 0.047 & 0.322 & 0.047 & 0.322 & 0.047 & 0.360 & 0.047 & 0.047 & 0.424 & 0.322 & 0.047 & 0.322 & \\
\hline GER & 0.107 & 0.107 & 0.107 & 0.507 & 0.383 & 0.283 & 0.283 & 0.107 & 0.107 & 0.493 & 0.107 & 0.107 & 0.383 & 0.283 & 0.283 & $5: \mathrm{F}^{*} \mathbf{h}^{*} \mathrm{R}^{*} \mathrm{~N}$ \\
\hline IRL & 0.105 & 0.047 & 0.105 & 0.047 & 0.683 & 0.047 & 0.317 & 0.047 & 0.105 & 0.047 & 0.047 & 0.105 & 0.222 & 0.047 & 0.222 & \multirow{4}{*}{ 6: $F^{*} h^{*} R^{*} n$} \\
\hline LUX & 0.328 & 0.047 & 0.328 & 0.047 & 0.665 & 0.047 & 0.335 & 0.047 & 0.328 & 0.047 & 0.047 & 0.328 & 0.332 & 0.047 & 0.332 & \\
\hline EST & 0.052 & 0.047 & 0.052 & 0.047 & 0.525 & 0.047 & 0.475 & 0.047 & 0.052 & 0.047 & 0.047 & 0.052 & 0.111 & 0.047 & 0.111 & \\
\hline POL & 0.065 & 0.047 & 0.065 & 0.047 & 0.503 & 0.047 & 0.497 & 0.047 & 0.065 & 0.047 & 0.047 & 0.065 & 0.100 & 0.047 & 0.100 & \\
\hline KOR & 0.047 & 0.053 & 0.053 & 0.047 & 0.047 & 0.727 & 0.247 & 0.047 & 0.047 & 0.047 & 0.053 & 0.053 & 0.047 & 0.273 & 0.247 & \multirow{4}{*}{ 7: $\mathrm{F}^{*} \mathrm{~h}^{*} \mathbf{r}^{*} \mathbf{N}$} \\
\hline USA & 0.201 & 0.231 & 0.231 & 0.201 & 0.201 & 0.664 & 0.336 & 0.201 & 0.201 & 0.201 & 0.231 & 0.231 & 0.201 & 0.284 & 0.284 & \\
\hline CZE & 0.063 & 0.063 & 0.063 & 0.325 & 0.231 & 0.554 & 0.231 & 0.063 & 0.063 & 0.325 & 0.063 & 0.063 & 0.231 & 0.446 & 0.231 & \\
\hline NED & 0.049 & 0.049 & 0.049 & 0.487 & 0.487 & 0.513 & 0.487 & 0.049 & 0.049 & 0.123 & 0.049 & 0.049 & 0.123 & 0.123 & 0.123 & \\
\hline ISR & 0.047 & 0.047 & 0.047 & 0.047 & 0.062 & 0.047 & 0.938 & 0.047 & 0.047 & 0.047 & 0.047 & 0.047 & 0.047 & 0.047 & 0.047 & \multirow[b]{2}{*}{ 8: $F^{*} h^{*} r^{*} n$} \\
\hline JPN & 0.231 & 0.145 & 0.391 & 0.145 & 0.231 & 0.145 & 0.609 & 0.126 & 0.126 & 0.126 & 0.126 & 0.126 & 0.126 & 0.126 & 0.126 & \\
\hline FIN & 0.143 & 0.143 & 0.143 & 0.143 & 0.143 & 0.143 & 0.143 & 0.601 & 0.221 & 0.376 & 0.399 & 0.221 & 0.221 & 0.376 & 0.221 & \multirow{3}{*}{ 9: $\mathbf{f}^{*} \mathbf{H}^{*} \mathbf{R}^{*} \mathbf{N}$} \\
\hline SWE & 0.053 & 0.053 & 0.053 & 0.053 & 0.053 & 0.053 & 0.053 & 0.559 & 0.215 & 0.220 & 0.441 & 0.215 & 0.215 & 0.220 & 0.215 & \\
\hline ESP & 0.324 & 0.316 & 0.316 & 0.365 & 0.324 & 0.316 & 0.316 & 0.502 & 0.324 & 0.498 & 0.316 & 0.316 & 0.324 & 0.316 & 0.316 & \\
\hline ICL & 0.047 & 0.047 & 0.047 & 0.047 & 0.047 & 0.047 & 0.047 & 0.047 & 0.708 & 0.047 & 0.047 & 0.292 & 0.098 & 0.047 & 0.098 & \multirow{3}{*}{ 10: $\mathrm{f}^{*} \mathrm{H}^{*} \mathbf{R}^{*} \mathrm{n}$} \\
\hline NZL & 0.131 & 0.047 & 0.131 & 0.047 & 0.131 & 0.047 & 0.131 & 0.047 & 0.680 & 0.047 & 0.047 & 0.320 & 0.169 & 0.047 & 0.169 & \\
\hline PRT & 0.480 & 0.047 & 0.248 & 0.047 & 0.439 & 0.047 & 0.248 & 0.047 & 0.520 & 0.047 & 0.047 & 0.248 & 0.439 & 0.047 & 0.248 & \\
\hline BEL & 0.053 & 0.053 & 0.053 & 0.298 & 0.189 & 0.298 & 0.189 & 0.053 & 0.053 & 0.621 & 0.053 & 0.053 & 0.189 & 0.379 & 0.189 & \multirow[b]{2}{*}{ 11: $f^{*} h^{*} R^{*} N$} \\
\hline UK & 0.082 & 0.082 & 0.082 & 0.494 & 0.321 & 0.342 & 0.321 & 0.082 & 0.082 & 0.506 & 0.082 & 0.082 & 0.321 & 0.342 & 0.321 & \\
\hline SUI & 0.049 & 0.049 & 0.049 & 0.049 & 0.049 & 0.049 & 0.049 & 0.105 & 0.105 & 0.105 & 0.786 & 0.214 & 0.105 & 0.157 & 0.157 & \multirow{4}{*}{ 12: $f^{*} H^{*} r^{*} N$} \\
\hline CAN & 0.119 & 0.119 & 0.119 & 0.119 & 0.119 & 0.119 & 0.119 & 0.139 & 0.139 & 0.139 & 0.638 & 0.362 & 0.139 & 0.148 & 0.148 & \\
\hline SLO & 0.091 & 0.234 & 0.194 & 0.091 & 0.091 & 0.234 & 0.194 & 0.091 & 0.091 & 0.091 & 0.635 & 0.194 & 0.091 & 0.365 & 0.194 & \\
\hline SVK & 0.098 & 0.125 & 0.098 & 0.125 & 0.098 & 0.125 & 0.098 & 0.205 & 0.098 & 0.205 & 0.547 & 0.098 & 0.098 & 0.453 & 0.098 & \\
\hline NOR & 0.052 & 0.047 & 0.052 & 0.047 & 0.047 & 0.047 & 0.047 & 0.047 & 0.059 & 0.047 & 0.047 & 0.941 & 0.047 & 0.047 & 0.047 & 13: $f^{*} H^{*} r^{*} n$ \\
\hline DEN & 0.049 & 0.047 & 0.047 & 0.047 & 0.282 & 0.047 & 0.047 & 0.047 & 0.049 & 0.047 & 0.047 & 0.047 & 0.718 & 0.047 & 0.047 & 14: $f^{*} h^{*} R^{*} n$ \\
\hline HUN & 0.060 & 0.060 & 0.060 & 0.277 & 0.120 & 0.277 & 0.120 & 0.060 & 0.060 & 0.325 & 0.060 & 0.060 & 0.120 & 0.675 & 0.120 & \multirow{2}{*}{ 15: $f^{*} h^{*} r^{*} N$} \\
\hline FRA & 0.047 & 0.065 & 0.047 & 0.065 & 0.047 & 0.065 & 0.047 & 0.158 & 0.047 & 0.158 & 0.489 & 0.047 & 0.047 & 0.511 & 0.047 & \\
\hline AUT & 0.562 & 0.047 & 0.438 & 0.047 & 0.148 & 0.047 & 0.148 & 0.047 & 0.098 & 0.047 & 0.047 & 0.098 & 0.098 & 0.047 & 0.098 & 16: $f^{*} h^{*} r^{*} n$ \\
\hline
\end{tabular}


Table 6. Changes and continuity of ideal types by OECD countries from Y1995 to Y2015.

\begin{tabular}{|c|c|c|c|c|c|}
\hline $\begin{array}{ll}\text { Country } & \text { Year } \\
\end{array}$ & 1995 & 2000 & 2005 & 2010 & 2015 \\
\hline Australia & $F^{*} h^{*} r^{*} n(8)$ & $F^{*} h^{*} r^{*} n(8)$ & $F^{*} h^{*} r^{*} n(8)$ & $F^{*} h^{*} r^{*} n(8)$ & $F^{*} H^{*} R^{*} n(2)$ \\
\hline Austria & $f^{*} H^{*} R^{*} n(10)$ & $f^{*} H^{*} R^{*} n(10)$ & $f^{*} H^{*} R^{*} n(10)$ & $\mathbf{f}^{*} \mathbf{H}^{*} \mathbf{R}^{*} \mathbf{n}(\mathbf{1 0 )}$ & $\mathrm{f}^{*} \mathrm{~h}^{*} \mathrm{r}^{*} \mathrm{n}(16)$ \\
\hline Belgium & $f^{*} h^{*} r^{*} N$ & $f^{*} h^{*} r^{*} N(15)$ & $f^{*} h^{*} r^{*} N$ & $f^{*} h^{*} R^{*} \mathbf{N}(11)$ & $f^{*} h^{*} R^{*} N(11)$ \\
\hline Canada & $f^{*} H^{*} R^{*} N(9)$ & $f^{*} H^{*} R^{*} N(9)$ & $f^{*} H^{*} r^{*} N(12)$ & $\mathbf{f}^{*} \mathbf{H}^{*} \mathbf{r}^{*} \mathbf{N}(12)$ & $f^{*} H^{*} r^{*} N(12)$ \\
\hline Chile & $f^{*} H^{*} R^{*} n(10)$ & $f^{*} H^{*} R^{*} n(10)$ & $f^{*} H^{*} R^{*} n(10)$ & $f^{*} H^{*} r^{*} n(13)$ & $F^{*} h^{*} r^{*} n(4)$ \\
\hline Czech Rep & $F^{*} h^{*} r^{*} N(7)$ & $F^{*} h^{*} r^{*} N(7)$ & $F^{*} h^{*} r^{*} N(7)$ & $F^{*} h^{*} r^{*} N(7)$ & $F^{*} h^{*} r^{*} N(7)$ \\
\hline Denmark & $F^{*} h^{*} R^{*} n(6)$ & $F^{*} h^{*} R^{*} n(6)$ & $F^{*} h^{*} R^{*} n(6)$ & $F^{*} h^{*} R^{*} n(6)$ & $f^{*} h^{*} R^{*} n(14)$ \\
\hline Estonia & $F^{*} h^{*} r^{*} n(8)$ & $F^{*} h^{*} r^{*} n(8)$ & $F^{*} h^{*} r^{*} n(8)$ & $F^{*} h^{*} R^{*} n(6)$ & $F^{*} h^{*} R^{*} n(6)$ \\
\hline Finland & $f^{*} H^{*} R^{*} N(9)$ & $f^{*} H^{*} R^{*} N(9)$ & $f^{*} H^{*} R^{*} N(9)$ & $f^{*} H^{*} R^{*} N(9)$ & $f^{*} H^{*} R^{*} N(9)$ \\
\hline France & $f^{*} H^{*} r^{*} N(12)$ & $f^{*} h^{*} r^{*} N$ & $f^{*} H^{*} r^{*} N(12)$ & $f^{*} h^{*} r^{*} N$ & $f^{*} h^{*} r^{*} N$ \\
\hline Germany & $F^{*} h^{*} r^{*} N(7)$ & $F^{*} h^{*} R^{*} N(5)$ & $f^{*} h^{*} R^{*} N(11)$ & $\mathbf{f}^{*} \mathbf{h}^{*} \mathbf{R}^{*} \mathbf{N}(11)$ & $F^{*} h^{*} R^{*} N(5)$ \\
\hline Greece & $F^{*} h^{*} r^{*} n(8)$ & $F^{*} h^{*} r^{*} n(8)$ & $F^{*} h^{*} r^{*} n(4)$ & $F^{*} H^{*} R^{*} n(2)$ & $F^{*} H^{*} R^{*} n(2)$ \\
\hline Hungary & $f^{*} h^{*} r^{*} n(16)$ & $f^{*} h^{*} r^{*} N(15)$ & $f^{*} h^{*} R^{*} N(11)$ & $f^{*} h^{*} R^{*} N(11)$ & $f^{*} h^{*} r^{*} N(15)$ \\
\hline Iceland & $f^{*} H^{*} R^{*} n(10)$ & $f^{*} H^{*} R^{*} n(10)$ & $f^{*} H^{*} R^{*} n(10)$ & $f^{*} H^{*} R^{*} n(10)$ & $f^{*} H^{*} R^{*} n(10)$ \\
\hline Ireland & $F^{*} h^{*} r^{*} n(8)$ & $F^{*} h^{*} R^{*} n(6)$ & $F^{*} h^{*} R^{*} n(6)$ & $F^{*} h^{*} R^{*} n(6)$ & $F^{*} h^{*} R^{*} n(6)$ \\
\hline Israel & $F^{*} h^{*} r^{*} n(8)$ & $F^{*} h^{*} r^{*} n(8)$ & $F^{*} h^{*} r^{*} n(8)$ & $F^{*} h^{*} r^{*} n(8)$ & $F^{*} h^{*} r^{*} n(8)$ \\
\hline Italy & $F^{*} H^{*} R^{*} n(2)$ & $F^{*} H^{*} R^{*} n(2)$ & $F^{*} H^{*} R^{*} n(2)$ & $F^{*} H^{*} R^{*} n(2)$ & $F^{*} H^{*} R^{*} n(2)$ \\
\hline Japan & $F^{*} h^{*} R^{*} N(5)$ & $F^{*} h^{*} r^{*} N(7)$ & $\mathrm{F}^{*} \mathbf{h}^{*} \mathbf{r}^{*} \mathbf{N}(7)$ & $F^{*} h^{*} r^{*} N(7)$ & $F^{*} h^{*} r^{*} n(8)$ \\
\hline Korea & $f^{*} h^{*} r^{*} n(16)$ & $f^{*} h^{*} r^{*} N$ & $f^{*} h^{*} r^{*} N$ & $F^{*} h^{*} r^{*} N(7)$ & $F^{*} h^{*} r^{*} N(7)$ \\
\hline Luxembourg & $\mathrm{F}^{*} \mathrm{H}^{*} \mathrm{R}^{*} \mathrm{~N}(\mathbf{1})$ & $f^{*} H^{*} R^{*} n(10)$ & $F^{*} h^{*} R^{*} n(6)$ & $F^{*} h^{*} r^{*} n(8)$ & $F^{*} h^{*} R^{*} n(6)$ \\
\hline Mexico & $\mathbf{F}^{*} \mathrm{H}^{*} \mathrm{R}^{*} \mathrm{~N}(\mathbf{1})$ & $F^{*} H^{*} R^{*} n(2)$ & $F^{*} H^{*} R^{*} N(1)$ & $F^{*} h^{*} r^{*} n(4)$ & $\mathrm{F}^{*} \mathrm{H}^{*} \mathbf{r}^{*} \mathrm{~N}(3)$ \\
\hline Netherlands & $\mathrm{F}^{*} \mathrm{~h}^{*} \mathrm{R}^{*} \mathrm{~N}(5)$ & $F^{*} h^{*} R^{*} N(5)$ & $F^{*} h^{*} R^{*} n(6)$ & $F^{*} h^{*} R^{*} N(5)$ & $F^{*} h^{*} r^{*} N(7)$ \\
\hline New Zealand & $\mathbf{f}^{*} \mathbf{H}^{*} \mathbf{R}^{*} \mathbf{n}(\mathbf{1 0})$ & $\mathbf{f}^{*} \mathbf{H}^{*} \mathbf{R}^{*} \mathbf{n}(\mathbf{1 0})$ & $\mathbf{f}^{*} \mathbf{H}^{*} \mathbf{R}^{*} \mathbf{n}(\mathbf{1 0})$ & $\mathbf{f}^{*} \mathbf{H}^{*} \mathbf{R}^{*} \mathbf{n}(\mathbf{1 0 )}$ & $\mathbf{f}^{*} \mathbf{H}^{*} \mathbf{R}^{*} \mathbf{n}(\mathbf{1 0 )}$ \\
\hline Norway & $f^{*} H^{*} r^{*} n(13)$ & $f^{*} H^{*} r^{*} n(13)$ & $f^{*} H^{*} r^{*} n(13)$ & $f^{*} H^{*} r^{*} n(13)$ & $f^{*} H^{*} r^{*} n(13)$ \\
\hline Poland & $F^{*} h^{*} r^{*} n(8)$ & $F^{*} h^{*} r^{*} n(8)$ & $F^{*} h^{*} r^{*} n(8)$ & $F^{*} h^{*} r^{*} n(8)$ & $F^{*} h^{*} R^{*} n(6)$ \\
\hline Portugal & $F^{*} H^{*} R^{*} n(2)$ & $F^{*} H^{*} R^{*} n(2)$ & $F^{*} H^{*} R^{*} n(2)$ & $f^{*} H^{*} R^{*} n(10)$ & $f^{*} H^{*} R^{*} n(10)$ \\
\hline Slovak Rep & $f^{*} H^{*} r^{*} N(12)$ & $f^{*} H^{*} r^{*} N(12)$ & $f^{*} H^{*} r^{*} N(12)$ & $\mathbf{f}^{*} \mathbf{H}^{*} \mathbf{r}^{*} \mathbf{N}(12)$ & $f^{*} H^{*} r^{*} N(12)$ \\
\hline Slovenia & $f^{*} H^{*} r^{*} N(12)$ & $f^{*} H^{*} r^{*} N(12)$ & $f^{*} H^{*} r^{*} N(12)$ & $f^{*} H^{*} r^{*} N(12)$ & $f^{*} H^{*} r^{*} N(12)$ \\
\hline Spain & $f^{*} h^{*} r^{*} N$ & $f^{*} H^{*} R^{*} N(9)$ & $f^{*} h^{*} R^{*} N(11)$ & $f^{*} H^{*} R^{*} N(9)$ & $f^{*} H^{*} R^{*} N(9)$ \\
\hline Sweden & $f^{*} H^{*} R^{*} N(9)$ & $f^{*} H^{*} R^{*} N(9)$ & $f^{*} H^{*} R^{*} N(9)$ & $f^{*} H^{*} R^{*} N(9)$ & $f^{*} H^{*} R^{*} N(9)$ \\
\hline Switzerland & $f^{*} H^{*} R^{*} N(9)$ & $f^{*} H^{*} r^{*} N(12)$ & $f^{*} H^{*} r^{*} N(12)$ & $f^{*} H^{*} r^{*} N(12)$ & $f^{*} H^{*} r^{*} N(12)$ \\
\hline Turkey & $f^{*} H^{*} r^{*} n(13)$ & $\mathrm{F}^{*} \mathrm{H}^{*} \mathbf{r}^{*} \mathrm{n}(4)$ & $\mathrm{F}^{*} \mathrm{H}^{*} \mathbf{r}^{*} \mathrm{n}(4)$ & $\mathrm{F}^{*} \mathrm{H}^{*} \mathbf{r}^{*} \mathrm{n}(4)$ & $\mathrm{F}^{*} \mathrm{H}^{*} \mathbf{r}^{*} \mathrm{n}(4)$ \\
\hline UK & $F^{*} h^{*} r^{*} N(7)$ & $F^{*} h^{*} r^{*} N(7)$ & $F^{*} h^{*} R^{*} N(5)$ & $F^{*} h^{*} R^{*} N$ & $f^{*} h^{*} R^{*} N$ \\
\hline USA & $F^{*} h^{*} R^{*} N(5)$ & $F^{*} h^{*} R^{*} N(5)$ & $F^{*} h^{*} r^{*} N(7)$ & $F^{*} h^{*} r^{*} N(7)$ & $F^{*} h^{*} r^{*} \mathbf{N}(7)$ \\
\hline
\end{tabular}

As shown in Table 7 below, the trend characteristics of the energy mix ideal type results (1995-2015) show that in 1995, the most common type was Type $8\left(F^{*} h^{*}{ }^{*} n\right.$, 'fossil fuel-centered type'), which included six countries including Israel. The most common type in 2000 was Type 8 and Type $10\left(f^{*} \mathrm{H}^{*} \mathrm{R}^{*} \mathrm{n}\right)$, including five countries respectively. In 2005 and 2010, Type $12\left(f^{*} \mathrm{H}^{*} \mathrm{r}^{*} \mathrm{~N}\right.$, 'hydro \& nuclear-centered type') emerged as the largest number of countries included with five countries in 2005 and four countries in 2010 including Switzerland. In 2015, the largest number of four countries was included as Type 12, but there are also two types (Type 7 and Type 6), each with the largest number of four countries.

In particular, Type $10\left(f^{*} \mathrm{H}^{*} \mathrm{R}^{*} \mathrm{n}\right)$ is a 'pan-renewable energy-centered type' in which hydroelectric and renewable energy sources are high. Since 1995, it has appeared continuously as a major energy mix ideal type. Throughout the all five stages from 1995 to 2015, the most number of twenty countries were Type $10\left(f^{*} \mathrm{H}^{*} \mathrm{R}^{*} \mathrm{n}\right)$, followed by Type $12\left(\mathrm{f}^{*} \mathrm{H}^{*} \mathrm{r}^{*} \mathrm{~N}\right.$, ‘hydro \& nuclear-centered type') with the second most number of nineteen countries. 
Table 7. Trend of the most ideal types results from Y1995 to Y2015.

\begin{tabular}{|c|c|c|c|c|c|}
\hline \multirow{2}{*}{ Year } & \multicolumn{5}{|c|}{$\longrightarrow \rightarrow \longrightarrow \longrightarrow$} \\
\hline & 1995 & 2000 & 2005 & 2010 & 2015 \\
\hline \multirow{8}{*}{ Type/Country } & $F^{*} h^{*} r^{*} n(8)$ & $F^{*} h^{*} r^{*} n(8)$ & $f^{*} H^{*} r^{*} N(12)$ & $f^{*} H^{*} r^{*} N(12)$ & $f^{*} H^{*} r^{*} N(12)$ \\
\hline & $\begin{array}{l}\text { 6: ISR, POL, EST, } \\
\text { IRL, GRC, AUS }\end{array}$ & $\begin{array}{l}\text { 5: ISR, EST, POL, } \\
\text { GRC, AUS }\end{array}$ & $\begin{array}{c}\text { 5: SUI, SLO, } \\
\text { CAN, PRT, FRA }\end{array}$ & $\begin{array}{l}\text { 4: SUI, SLO, } \\
\text { CAN, SLK }\end{array}$ & 4: SUI, CAN, SLO, SLK \\
\hline & $\mathrm{f}^{*} \mathrm{H}^{*} \mathrm{R}^{*} \mathrm{n}(\mathbf{1 0 )}$ & $\mathrm{f}^{*} \mathrm{H}^{*} \mathrm{R}^{*} \mathrm{n}(10)$ & $\mathrm{f}^{*} \mathrm{H}^{*} \mathrm{R}^{*} \mathrm{n}(10)$ & $f^{*} H^{*} R^{*} n(10)$ & $F^{*} h^{*}{ }^{*} N(7)$ \\
\hline & $\begin{array}{c}\text { 4: NZL, CHI ISL, } \\
\text { AUT }\end{array}$ & $\begin{array}{c}\text { 5: ISL, NZL, LUX, } \\
\text { AUT, CHI }\end{array}$ & $\begin{array}{l}\text { 4: ISL, NZL, } \\
\text { AUT, CHI }\end{array}$ & $\begin{array}{l}\text { 4: ISL, NZL, } \\
\text { PRT, AUT }\end{array}$ & 4: KOR, USA, CZE, NED \\
\hline & $f^{*} H^{*} R^{*} N(9)$ & $f^{*} H^{*} R^{*} N(9)$ & $F^{*} h^{*} r^{*} n(8)$ & $F^{*} h^{*} r^{*} n(8)$ & $F^{*} h^{*} R^{*} n(6)$ \\
\hline & $\begin{array}{l}\text { 4: SWE, FIN } \\
\text { CAN, SUI }\end{array}$ & $\begin{array}{c}\text { 4: SWE, FIN, ESP, } \\
\text { CAN }\end{array}$ & $\begin{array}{c}\text { 4: ISR, EST, POL, } \\
\text { AUS }\end{array}$ & $\begin{array}{l}\text { 4: ISR, AUS, } \\
\text { LUX, POL }\end{array}$ & 4: IRL, LUX, EST, POL \\
\hline & & & $F^{*} h * R^{*} n(6)$ & $F^{*} h^{*} r^{*} N(7)$ & $f^{*} H^{*} R^{*} n(10)$ \\
\hline & & & $\begin{array}{l}\text { 4: DEN, IRL, } \\
\text { NED, LUX }\end{array}$ & $\begin{array}{l}\text { 4: KOR, USA, } \\
\text { JPN, CZE }\end{array}$ & 3: ISL, NZL, PRT \\
\hline
\end{tabular}

\section{Conclusions and Implications}

This study has attempted to analyze the global trends of energy mix and energy transition in chronological view (from Y1995 to Y2015) and identify the actual results based on the empirical findings through the Fuzzy-set ideal type analysis. We have looked at the research question: how the ideal types of the energy mix in the OECD countries form and what implications they have in the context of energy transition. In short, this paper reveals that twelve ideal types of the energy mix of thirty-four OECD countries were derived in Y1995, eleven ideal types in Y2000, thirteen ideal types in Y2005, twelve ideal types in Y2010, and fifteen ideal types in Y2015, respectively. In particular, the results of the fuzzy-set method are beneficial in that they present the new joint features of ideal types of energy mix and transition of OECD countries by utilizing existing global energy source data: 'Fossil fuel sources'(F), 'Hydroelectric sources' (H), 'Renewable sources' (R), and 'Nuclear sources' (N).

In terms of Energy Mix, this study has found that particularly in 2015, S. Korea (Fuzzy-set membership score, 0.727), USA (0.664), Czech Rep. (0.554), and Netherlands (0.513) belonged to Type $7\left(\mathrm{~F}^{*} \mathrm{~h}^{*} \mathrm{r}^{*} \mathrm{~N}\right.$, 'pan-conventional energy-centered mix') led by the conventional energy sources including fossil fuel and nuclear power; and Israel (0.938) and Japan (0.609) belonged to Type 8 $\left(f^{*} h^{*} r^{*} \mathrm{~N}\right.$, 'fossil fuel-centered energy mix'). Also, Hungary (0.675) and France (0.511) belonged to Type $15\left(f^{*} h^{*} r^{*} \mathrm{~N}\right.$, 'nuclear-centered energy mix'). On the other hand, Iceland (fuzzy-set membership score, 0.708$)$, New Zealand (0.680), and Portugal (0.520) belonged to Type $10\left(f^{*} H^{*} R^{*} n\right.$, 'pan-renewable

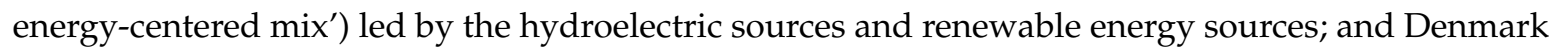
(0.718) was included in Type $14\left(f^{*} h^{*} R^{*} n\right.$, 'renewable energy-centered mix'). Figure 1 below shows the main results of energy mix in 2015.

In regards to Energy Transition, from 1995 to 2010, in the case of Type 7 ('pan-conventional energy-centered mix') and Type 8 ('fossil fuel-centered energy mix'), seven to eight countries were steadily included, but in 2015 there was a significant decrease to four countries (solely Type 7). However, in the case of Type $10\left(f^{*} H^{*} R^{*} n\right.$, 'pan-renewable energy-centered mix') and Type $14\left(f^{*} h^{*} R^{*} n\right.$, 'renewable energy-centered $\mathrm{mix}^{\prime}$ ), four to five countries were consistently included without significant change from 1995 to 2015.

Even in the case of individual countries of 34 OECD countries, there has never been an epoch-making transition from Type 7 ('pan-conventional energy-centered mix'), Type 8 ('fossil fuel energy-centered mix'), or Type 15 ('nuclear energy-centered mix') to Type 10 ('pan-renewable energy-centered mix') or Type 14 ('renewable energy-centered mix') for 20 years. Meanwhile, in the case of Denmark, Type $6\left(f^{*} h^{*} R^{*} n\right.$, 'fossil fuel \& renewable energy-led mix') had continued from 1995 to 2010, but there was a transition into Type 14 ('renewable energy-centered mix') in 2015, which has shown significant results. In fact, the share of renewable energy generation in Denmark was only $5.0 \%$ in 1995, but it accounted for the highest proportion of $60.7 \%$ in 2015 , with a rapid increase of approximately 12 times over 20 years. Specific attention is given to Denmark as it is currently able to 
supply up to $140 \%$ of the country's total electricity demand with only wind power. The remaining electricity is supplied to neighboring countries, Norway, Germany, and Sweden [9,17,47].

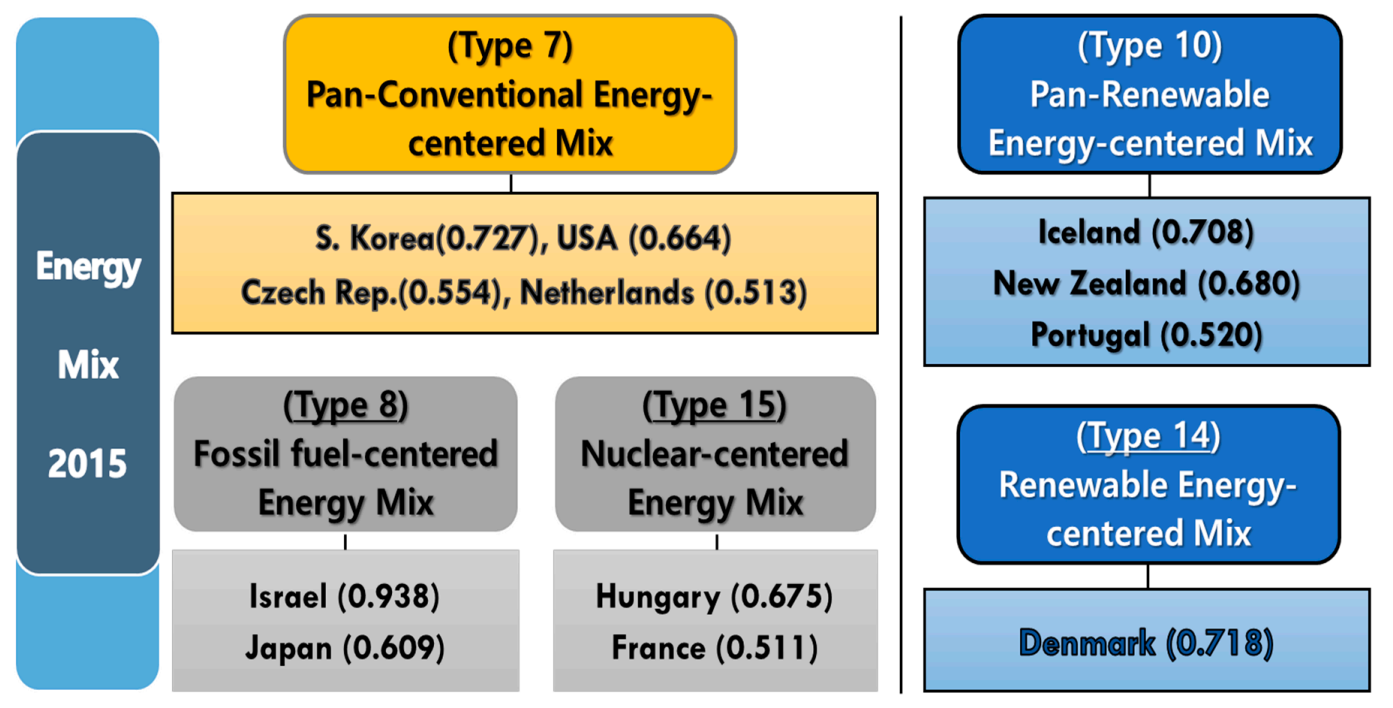

Figure 1. The main results of Energy Mix 2015.

In Portugal, Type $2\left(\mathrm{~F}^{*} \mathrm{H}^{*} \mathrm{R}^{*} \mathrm{n}\right.$, 'nuclear energy-marginalized mix') was maintained until 2005, but in 2010, it was converted to Type $10\left(f^{*} H^{*} R^{*} n\right.$, 'pan-renewable energy-centered mix'). In fact, Portugal's renewable energy generation rate in 1995 was only $3.2 \%$ of the total, but by 2015 it had risen $30.3 \%$, an approximately 9 -fold increase in 20 years $[9,48]$. In the UK, Type $7\left(\mathrm{~F}^{*} \mathrm{~h}^{*} \mathrm{r}^{*} \mathrm{~N}\right.$, 'pan-conventional energy-centered mix') continued until 2000, then changed to Type $5\left(F^{*} h^{*} R^{*} \mathrm{~N}\right)$ in 2005 and 2010, and was converted into Type $11\left(f^{*} h^{*} R^{*} N\right.$, 'renewable \& nuclear energy-centered mix') in 2015. In other words, in the 1990s, conventional energy generation became popular, in the 2000s renewable energy development also increased, and by 2015, fossil fuel power generation became rather weak. The proportion of renewable energy generation in 2015 was $23.0 \%$, which was about 38 times higher than the $0.6 \%$ of $1995[9,49]$.

This study highlights that the relative expansion of the proportion of new and renewable energy in these countries is an important change because, in the setting of the existing energy mix, the renewable energy has been neglected due to the fluctuation of physical supply availability $[17,47,50]$. The main purpose of the energy mix was to precisely set a configuration based on fossil fuels and nuclear power, which have been supplied and controlled easily $[28,49,50]$. In this paper, the 20-year trend of the energy mix in 34 OECD countries through the Fuzzy-set of ideal type analysis, reveals the gradual change of the features of energy transition, although an epoch-making trend of overall energy transition in OECD countries is not identified. In addition, the analysis of the energy mix ideal type of individual countries reveals the change in energy mix characteristics and the context of energy transition.

However, in spite of these significant findings, this study has limited ability to explain energy transition only from the transition of hard energy (fossil fuel and nuclear energy) to the soft energy (renewable energy) in the 34 OECD case countries. In fact, the energy transition has a characteristic of the transformative aspect of the sociotechnical system in which the political, economic, environmental, and social elements are simultaneously changing and rearranged, and the aspect of the implementation of multilateral governance in which various entities participate $[10,51,52]$. To overcome these limitations, various follow-up studies will be needed to study the relevant contexts of each OECD country's detailed case in relation to energy transition based on a sociotechnical system.

Author Contributions: T.H., the first author designed the very structure of the article and completed the writing-up under the cooperation with co-authors. Y.-C.C., as the co-author, contributed in revising the article as a whole. Last but not least, the other co-author, J.H.K. has also aided in completing the writing-up as well as the proofreading. 
Funding: This research received no external funding.

Conflicts of Interest: The authors declare no conflict of interest.

\section{References}

1. Smil, V. Energy at the Crossroads; MIT Press: Cambridge, MA, USA, 2003.

2. REN21 Global Status Report. In Renewable Energy Policy Network for the 21st Century; REN21: Paris, France, 2015.

3. Korea New\&Renewable Energy (KNREA). Renewable Energy Brief, Trend Data 16-6; KNREA: Seoul, Korea, June 2016.

4. Palanichamy, C.; Naveen, P.; Muthusundar, S.K. A sustainable renewable energy mix option for the secluded society. J. Renew. Sustain. Energy 2014, 6, 023124. [CrossRef]

5. Roorda, C.; Wittmayer, J. Transition Management in Five European Cities-An Evaluation; DRIFT: Rotterdam, The Netherlands, 2014.

6. Korea Energy Economics Institute (KEEI). Energy Policy Prospect of EU Countries. World Energy Market Insight, 16 March 2016.

7. Hong, S.; Bradshaw, C.J.A.; Brook, B.W. Evaluating options for the future energy mix of Japan after the Fukushima nuclear crisis. Energy Policy 2013, 56, 418-424. [CrossRef]

8. Betsill, M.; Bulkeley, H. Cities and the Multilevel Governance of Global Climate Change. Global Governance. Rev. Multilater. Int. Organ. 2006, 12, 141-159.

9. Samjong KPMG Economic Research Institute (ERI). 2018 Major Issues and Issues in the Energy Sector; ERI: Seoul, Korea, 2018.

10. Edmondsona, D.L.; Kerna, F.; Roggea, K.S. The co-evolution of policy mixes and socio-technical systems: Towards a conceptual framework of policy mix feedback in sustainability transitions. Res. Policy 2018, in press. [CrossRef]

11. U.S. Energy Information Administration (EIA). Annual Energy Outlook; EIA: Washington, DC, USA, 2018.

12. Intergovernmental Panel on Climate Change (IPCC). Special Report on Renewable Energy Sources and Climate Change Mitigation; Intergovernmental Panel on Climate Change: Geneva, Switzerland, 2011.

13. Loorbach, D.; Brugge, R.; Taanman, M. Governance in the energy transition: Practice of transition managemtacent in the Netherlands. Int. J. Environ. Technol. Manag. 2008, 9, 294-315. [CrossRef]

14. Loorbach, D. Transition Management for Sustainable Development: A Prescriptive, Complexity-Based Governance Framework. Governance Int. J. Policy Admin. Inst. 2010, 23, 161-183. [CrossRef]

15. International Energy Agency (IEA). Energy Policies of IEA Countries; IEA: Paris, France, 2017.

16. LAZARD. Lazard's Levelized Cost of Energy Analysis-Version 10.0; LAZARD: New York, NY, USA, 2016.

17. Korea Energy Economics Institute (KEEI). Renewable Energy Supply Target and Support System Status. World Energy Market Insight, 17 February 2017.

18. Jacobssona, S.; Lauber, V. The politics and policy of energy system transformation-Explaining the German diffusion of renewable energy technology. Energy Policy 2006, 34, 256-276. [CrossRef]

19. Morrison, D.E.; Lodwick, D.G. The Social Impacts of Soft and Hard Energy Systems: The Lovins' Claims as a Social Science Challenge. Annu. Rev. Energy 1981, 6, 357-378. [CrossRef]

20. Kern, F.; Smith, A. Restructuring energy systems for sustainability? Energy transition policy in the Netherlands. Energy Policy 2008, 36, 4093-4103. [CrossRef]

21. Korea Economic Research Institute (KERI). Trends and Implications of Energy Transiton Policy in Germany, KERI Brief; KERI: Seoul, Korea, 2016; pp. 14-16.

22. Rotmans, J.; Kemp, R.; Asselt, M. More evolution than revolution: Transition management in public policy. Foresight 2001, 3, 15-31. [CrossRef]

23. Kemp, R.; Rotmans, J.; Loorbach, D. Assessing the Dutch Energy Transition Policy: How Does it Deal with Dilemmas of Managing Transitions? J. Environ. Policy Plan. 2007, 9, 315-331. [CrossRef]

24. Geels, F. The dynamics of transitions in socio-technical systems: A multi-level analysis of the transition pathway from horse-drawn carriages to automobiles (1860-1930). Technol. Anal. Strateg. Manag. 2005, 17, 445-476. [CrossRef]

25. Geels, F.; Schot, J. Typology of sociotechnical transition pathways. Res. Policy 2007, 36, 399-417. [CrossRef] 
26. Loorbach, D. Transition Management: New Mode of Governance for Sustainable Development; International Books: Utrecht, The Netherlands, 2007.

27. Réseau de transport d'électricité (RTE). Generation Adequacy Report on the Electricity Supply-Demand Balance in France: 2016 Edition; Réseau de Transport d'Électricité: Paris, France, 2016.

28. Lee, Y.W.; Lee, H.N.; Ryu, J.S. Enactment and Future Prospect of Energy Transition Law in France; Nuclear Policy Research-Brief Report 44; NPRI: Washington, DC, USA, April 2018.

29. Choi, Y.J. Social science method: Fuzzy ideal center of analysis and factor analysis. J. Gov. Stud. 2009, 15, 307-337.

30. Schneider, C.Q.; Rohlfing, I. Case studies nested in fuzzy-set QCA on sufficiency: Formalizing case selection and causal inference. Sociol. Methods Res. 2016, 45, 526-568. [CrossRef]

31. Ragin, C.C. Fuzzy-Set Social Science; University of Chicago Press: Chicago, IL, USA, 2000.

32. Ragin, C.C. Redesigning Social Inquiry Fuzzy Sets and Beyond; University of Chicago Press: Chicago, IL, USA, 2008.

33. Rihoux, B. Qualitative Comparative Analysis (QCA) and Related Systematic Comparative Methods: Recent Advance and Remaining Challenges for Social Science Research. Int. Sociol. 2006, 21, 679-706. [CrossRef]

34. Gough, I. Globalizatoin and regional welfare regimes: The east asian case. Glob. Soc. Policy 2001, 1, $163-189$. [CrossRef]

35. Bambra, C. The Worlds ofWelfare: Illusory and Gender Blind? Soc. Policy Soc. 2004, 3, 201-211. [CrossRef]

36. Katz, H.; Helmut, K.A.; Marcus, M.L. Fuzzy set approaches to the study of global civil society. Glob. Civ. Soc. 2006, 7, 186-196.

37. Yang, J.J.; Jung, Y.R. An Empirical Research of the Underdevelopment of the Welfare State. Korean Polit. Sci. Rev. 2012, 46, 79-97. [CrossRef]

38. Seok, J.E. Towards a Sustainable Welfare State: An Evaluation and Typology of OECD Countries Through the Fuzzy-set Ideal Types Analysis. Health Soc. Welf. Rev. 2014, 34, 5-35. [CrossRef]

39. Kvist, J. Welfare reform in the Nordic countries in the 1990s: Using fuzzy-set theory to assess conformity to ideal types. J. Eur. Soc. Policy 1999, 9, 231-252. [CrossRef]

40. Kvist, J. Fuzzy set ideal type analysis. J. Bus. Res. 2007, 60, 474-481. [CrossRef]

41. World Bank (WB). World Development Indicators; World Bank: Washington, DC, USA, 1995.

42. World Bank (WB). World Development Indicators; World Bank: Washington, DC, USA, 2000.

43. World Bank (WB). World Development Indicators; World Bank: Washington, DC, USA, 2005.

44. World Bank (WB). World Development Indicators; World Bank: Washington, DC, USA, 2010.

45. World Bank (WB). World Development Indicators; World Bank: Washington, DC, USA, 2015.

46. Connolly, D.; Lund, H.; Mathiesen, B.V. Smart Energy Europe: The technical and economic impact of one potential 100\% renewable energy scenario for the European Union. Renew. Sustain. Energy Rev. 2016, 60, 1634-1653. [CrossRef]

47. Nolden, C. Governing community energy-Feed-in tariffs and the development of community wind energy schemes in the United Kingdom and Germany. Energy Policy 2013, 63, 543-552. [CrossRef]

48. Wierling, A.; Schwanitz, V.J.; Zeiß, J.P.; Bout, C.; Candelise, C.; Gilcrease, W.; Gregg, J.S. Statistical Evidence on the Role of Energy Cooperatives for the Energy Transition in European Countries. Sustainability 2018, 10, 3339. [CrossRef]

49. Foxon, T.J. Transition pathways for a UK low carbon electricity future. Energy Policy 2013, 52, 10-24. [CrossRef]

50. Markewitz, P.; Robinius, M.; Stolten, D. The Future of Fossil Fired Power Plants in Germany-A Lifetime Analysis. Energies 2018, 11, 1616. [CrossRef]

51. Rogge, K.S.; Pfluger, B.; Geels, F.W. Transformative policy mixes in socio-technical scenarios: The case of the low-carbon transition of the German electricity system (2010-2050). Technol. Forecast. Soc. Chang. 2018, in press. [CrossRef]

52. Rogge, K.S.; Kern, F.; Howlett, M. Conceptual and empirical advances in analysing policy mixes for energy transitions. Energy Res. Soc. Sci. 2017, 33, 1-10. [CrossRef]

(C) 2018 by the authors. Licensee MDPI, Basel, Switzerland. This article is an open access article distributed under the terms and conditions of the Creative Commons Attribution (CC BY) license (http:/ / creativecommons.org/licenses/by/4.0/). 